\title{
Configuration of Product-Service Systems value networks - Evidence from an innovative sector for sludge treatment
}

\author{
Khaled Medini *, Xavier Boucher \\ Ecole Nationale Supérieure des Mines de Saint-Etienne, 158 Cours Fauriel, Saint-Étienne 42023, France
}

Product-Service Systems are increasingly emerging in response to market volatility and more demanding customer requirements. Their development process, however, is not as straightforward as for traditional physical goods. For instance, the configuration of a Product-Service System entails taking several factors into account, such as the points of view of the different actors in the value network. This paper proposes a methodological framework supported by modelling and simulation to evaluate the performance of different configurations of the value network, referred to as scenarios, and the impact of different input parameters within these scenarios. The proposed approach is illustrated by a case study which highlights the main drivers of a new innovative sector for sludge treatment.

\section{Introduction}

Market volatility and customer requirements are obliging companies to seek new customer-centred business strategies to provide customers with more added value and highly personalized solutions. This situation has led to the emergence of new services in the business field. Business is currently shifting from traditional physical products to a combination of products and services, known as Product-Service-Systems (PSS). The strategic and organizational transition from a manufacturing-oriented company to a PSS-oriented company is known in the scientific literature as 'servitization' [1-4]. This servitization process involves complex changes for the decision-makers of the focal company leading the PSS offer design and implementation, but also all the other companies collaborating in such integrated offers. Baines defines servitization as "the innovation of an organization's capabilities and processes to better create mutual value through a shift from selling products to selling PSS" [5]. Such a transition involves major challenges in terms of organizational transformations, process reconfiguration and cultural change.

Although the scientific literature indicates that consistent advances have already been made in the technical engineering of PSS solutions [6], there is still a lack of tools and methods to support the organizational transition induced by the servitization shift, in particular at operational level [7-9,42]. In addition to

\footnotetext{
* Corresponding author. Tel.: +33477429317.

E-mail address: khaled.medini@emse.fr (K. Medini).
}

guidelines for the implementation of a PSS, decision-makers need feedback on the viability of a PSS solution prior to its implementation. PSS are based on a complex integration of product and service components, requiring the interoperability of several collaborative companies in the delivery network. The literature underlines that, before designing the detailed structure of a PSS, the viability of the solution in terms of the overall architecture of the system and its delivery network need to be assessed $[6,10]$. More specifically, PSS introduce new economic balances based on selling the use instead of the product. These balances are very sensitive to variations of the final PSS users' behaviours [11]. The anticipation of these economic impacts remains an important gap for PSS design [12]. The development of decision-making approaches meeting such requirements remains an important objective. Furthermore, generally speaking a PSS cannot be delivered by a single company meaning that the whole value network involved in the delivery process should be considered in the evaluation. Hence, a multi-actor perspective is crucial to assess the economic and technical viability, involving the various actors of the value network [7-9,13,14]. These peculiarities of the PSS context introduce a significant amount of risk underpinning the PSS implementation. Hence, an upfront assessment whether the intended business model will generate profit is crucial and proper tools are needed for this purpose.

In this perspective, simulation is one of the most common tools used in the PSS context to enable well-informed decisions on PSS alternatives $[10,13,15-18,32]$. Here the alternatives refer to the various PSS offers and are evaluated from a single perspective, i.e. customer point of view or company point of view. However, the 
various possible scenarios of delivery networks are poorly addressed and evaluation often uses classical performance indicators such as cost and lead time, despite some improvements proposing performance monitoring to PSS [19]. Thus, there is no clear support to the decision making process on how to proceed with the design of the overall architecture of PSS solutions, considered with their delivery networks. Basically, this highlights the lack of multi-actor perspective in the evaluation of PSS alternatives and methodological guidance throughout the design and implementation processes of these alternatives [7-9].

In order to support the industrial shift towards PSS, the first aim of this research work is to provide decision-makers with methodological and technical solutions to evaluate whether a PSSoriented business model is economically viable and to assess the practical implications of alternative configurations of the PSS value networks. Simulation is included in this methodological approach to enable the virtualization of a large panel of performance drivers' variations. The decision-makers concerned are those in charge of designing the overall architecture of PSS solutions together with their value networks. They can belong to the various stakeholders of the required PSS delivery network.

Beyond the development of a decision support system dedicated to a specific PSS case study, a second and complementary objective of this paper consists in structuring a generic framework for PSS modelling and analysis, aimed at supporting the generalization and re-use of generic components of the decision support system. This methodological framework supports the development and implementation of contextualized Decisions Support Systems dedicated to the analysis of PSS network configuration, then the use of these DSS to generate concrete analyses of PSS case studies.

A case study in the sludge treatment sector is used to illustrate the proposed approach and helps identifying the main drivers for the economic performance of the PSS value networks considered. The case study pointes out some key performance drivers for the innovative sector of industrial sludge treatment and discusses the relevance of the developed decision support system to the analysis of alternative business models viability.

The rest of the paper is organized as follows. Section 'Literature review and research positioning' reviews the literature to identify PSS development methodologies and requirements. The PSS design framework is presented in section 'Proposed framework' which joins the requirements identified from the literature to previous research outputs in the PSS domain. The illustration with a case study and the result analyses are detailed in section 'Case study in the sludge treatment sector'. The paper ends with concluding remarks and perspectives in section 'Conclusions and research perspectives'.

\section{Literature review and research positioning}

A non-exhaustive literature review was performed in order to provide the theoretical foundations of the paper, by shedding more light on the most common PSS design requirements. The search for articles was limited to the ScienceDirect database and to the last decade. A recent literature review revealed that the Journal of Cleaner Production, Journal of Manufacturing Technology Management, and CIRP Journal of Manufacturing Science and Technology were among the journals with the highest PSS publication frequency over the last decade [9]. Thus, the focus was put on these journals as well as the Proceedings of the Industrial Product-Service Systems Conference. The first filtering criterion relates to the relevance of article titles to PSS design, performance and simulation. The second filtering criterion is the papers' abstracts allowing for the number of papers to be considerably reduced.
In coherence with the current research orientation, 3 key topics are highlighted: stakeholder integration, PSS design and configuration, PSS simulation and assessment. Further research gaps and requirements are identified and summarized towards the end of this section.

As predicted by many authors over the last decade, service advantages are progressively starting to dominate the business world [7,20-22]. Services are being combined with products to provide customer-centred and integrated solutions. According to Meier et al. [7], an Industrial PSS is characterized by the "integrated and mutually determined planning, development, provision and use of product and service shares including its immanent software components in Business-to-Business applications and represents a knowledge-intensive socio-technical system". PSSs represent high benefit potential to all the actors involved. Higher revenues, longer business relationships and lower resource consumption are some of the benefits to the PSS provider. As for the customer, PSS could lead to a higher level of productivity and lessen customer responsibility with regard to physical products [7,9]. Furthermore, PSS has the potential to reduce the environmental impact of capital goods through dematerialization $[9,13,23,24]$. To promote these benefits, proper methodologies are needed to jointly develop products and services and monitor PSSs throughout the product lifecycle $[7,13,25]$. The following sections shed more light on the need for stakeholder integration and PSS design and configuration approaches, in order to clearly point out the gaps in this field (section 'PSS design requirements').

\section{Stakeholder integration}

As observed by many authors in the PSS literature, all the stakeholders interested in the PSS should be involved in the design process [7,8,26,27]. Morelli [26] proposed a set of PSS engineering methods focused on the representation of the PSS and PSS partners. The author stressed the need for collaboration between PSS value network actors as well as external stakeholders in order to support an integrated PSS solution. Accordingly, a PSS network should be designed prior to developing the PSS solution, which supports both the design and operation phases of the PSS solution. This is because the PSS, unlike traditional manufactured products, draws upon a lot of internal and external resources [10,27]. Additionally, PSS development requires not only technological knowledge on products and services but also regulations and the cultural backgrounds of the actors. This increased complexity in the design and delivery of PSS solutions induces a need to integrate multiple know-how and a full service network, in particular when considering PSS customers at territorial level [8]. Subsequently, customer satisfaction with the PSS depends on the way services are delivered. Thus, it is important to gather customer requirements properly by involving them in the PSS design and value-creation processes [14,28]. Consequently, stakeholder integration gives rise to efficient design of PSS solutions and mitigation of the risks accompanied with the servitization process [8]. Such risks can be further mitigated by designing proper assessment tools and methods to be applied to the evaluation of alternative PSS network configurations. This highlights research needed in the development of consistent PSS assessment solutions with real integration of stakeholder points of view.

\section{PSS design and configuration}

In the PSS literature the focus is put on the product and service design process itself, while methods relating to PSS configuration and evaluation remain scarce.

Marques et al. [25] proposed a generic PSS development methodology relying on the integrated design of product and 
service. The main steps of the methodology are: planning which involves identification of ideas and requirements, design relating to concept development, and post-processing which is about testing and implementing the PSS solution. The prerequisite of this methodology is that organizational change has already been implemented. However, the method only provides a conceptual framework for PSS development and not much support at operational level. Consistently with the stakeholder integration principle, Lelah et al. [29] assume that the transition to PSS involves different actors and variables in the decision-making process and that scenarios are a proper tool for putting pieces of the puzzle together in order to support the decision-making process. A scenario can be defined as a "description of a possible future that reflects different perspectives on the past, the present and the future". Scenarios represent different variables and share a common understanding of the future situation [29,30]. As such, scenarios allow for different strategies to be tested and the recognition of potential threats prior to implementation of the PSS solution.

Mannweiler et al. [31] linked the scenarios to the configuration process of the PSS offer. Accordingly, the factors that make the difference between one scenario and another are the so-called PSS variants. In fact, to fulfil a customer request, an individual PSSconfiguration is necessary. In general, a configuration can be defined as a process that enables the compilation (selection and combination) of predefined set of components. In the PSS context, both physical products and service activities need to be selected and combined. In compliance with the abovementioned multi-actor perspective, it is important to manage performer' assignments for all activities, among the various actors of the value network. This raises many flexibility opportunities and, at the end of the configuration process, many PSS variants can be proposed to fulfil customer needs. More recently, Medini et al. [14] used scenarios to model a set of envisioned PSS implementation alternatives within a servitization process. The scenarios are defined based on context analysis basically allowing for the main PSS-related opportunities and risks to be identified.

\section{PSS simulation and assessment}

In a state of the art article, Baines et al. [24] reviewed PSS typologies and identified an appealing need for methods and tools to assess the value created by the PSS, and particularly quantitative methods aimed at helping decision-makers in PSS implementation alternatives. In fact, testing the quality of a service is challenging since services are consumed in the second that they are produced. Therefore, simulation is a suitable tool for simulating whether the service will deliver the value it is intended to. Several methods were subsequently proposed in keeping with the above need. Kimita et al. [32] proposed a service cost simulation method in consideration of stochastic elements with the service such as human behaviour. They used extended service blueprint and activity-based costing as a starting point and computed the total service cost using discrete event simulation. In this sense, Mannweiler et al. [31] proposed a qualitative evaluation method of the PSS life cycle cost to support customer choice among the PSS variants. Marquès et al. [10] used discrete event simulation to evaluate the impact of the transition to PSS on the capacity management. They came to the conclusion that capacity planning has a critical role in transition success. Yoon et al. [33] proposed an evaluation method supporting PSS design using a relatively structured evaluation process and discrete event simulation. However, the positioning of the simulation is not clear in the methodology. Starting from the need to design PSS on the basis of value in use, Kimita and Shimomura [27] proposed a set of guidelines on how to efficiently design a customer-centred PSS.
They assume that a customer-centred evaluation of the PSS is needed since the PSS and its design process heavily involve the customer. They highlighted, however, that the design process requires both internal resources (e.g. production system) and the involvement of the whole PSS network. In another recent article, Taisch et al. [19] linked PSS monitoring to performance management by proposing a toolset to select performance indicators to monitor service performance in virtual enterprises. A prerequisite of the toolset is the collaboration between companies to achieve common goals. The toolset involves the identification of servitization functions, objectives and decision variables through a governance framework and the selection of performance indicators. Medini et al. [34] used a combined simulation and performance evaluation approach to configure PSS value networks. The simulation relies on a continuous deterministic model. These various advances underlined the interesting potential relying on simulation. The question raised in the following section is: how can such simulation approaches be integrated into remaining research gaps for better PSS design methods.

\section{PSS design requirements}

Based on the above literature review, 3 research gaps prompting the current research are identified as follows. First, although the gap relating to stakeholder integration was identified a few years ago, there is still a lack of methodologies involving all the PSS stakeholders. For instance, the methods identified in the literature incorporate an evaluation of the PSS solutions from a single point of view, that is the customer's [31] or PSS-provider's $[10,19,32]$. The need is twofold: to provide pertinent performance assessment for the distinct points of view to be considered, but also to provide the appropriate methods for multi-point of view decision analysis.

Second, PSS design and engineering requires effective support for industrial decision-makers, based on an operational and contextualized decision aid ('operational' refers to the ability to deliver concrete results, while 'contextualised' refers to the ability to capture accurate and useful contextualized data supporting the decision-making process). The current identified research works come under 2 main categories:

(1) A majority of the proposals identified from the literature are focused on providing qualitative guidelines for the effective development of PSS, or at most some tools covering single steps of the PSS design process (e.g. [26,27,29]). Accordingly, the need for operational results is not properly addressed.

(2) A few quantitative approaches are being used in the PSS context, however, the multi-actor perspective is poorly covered and the contextualization of the design process, poorly addressed (due to the focus on generic approaches impeding the applicability of the proposed methods (e.g. [25]).

One research orientation likely to fill these gaps and meet practitioner expectations consists in developing decision support system solutions which would offer both clear methodological guidance for contextualization together with concrete and operational decision aid. Simulation and PSS performance assessment would be the main pillars of such decision aids.

Additionally, support is needed from the early design stage of the PSS involving decisions on both the PSS architecture and network. This design stage is of key importance because of the huge impact of the decisions therein on the whole PSS life cycle. Hence, the multi-actor perspective mentioned above is definitely required here. This induces the need for rigorous modelling of the PSS actor network and flexibility in configuring alternative organizational scenarios. 


\section{Proposed framework}

The framework stems from previous research work in this field. It builds on the requirements identified from the literature which suggests that operational solutions are required and that a multiactor perspective is a key in the assessment of PSS alternatives, considering a life cycle perspective, and previous research outputs on methodological guidance and simulation as a means for PSS scenario evaluation [14,34]. More specifically, the framework provides methodological guidance supported by a contextualization process, dedicated to the joint assessment of the PSS offer and its network. It addresses the multi-actor perspective during the context analysis, organizational scenario definition and assessment. Decision support is provided through quantitative results of the scenario assessment. All these key elements of the framework will be detailed below.

\section{Methodological framework}

The objective of this methodological framework is to support the rapid development of Decision Support Systems, dedicated to PSS value-chain configuration. The decisional context addressed by the framework involves multiple decision centres representing the actors of the PSS value network. Additionally, it suggests that each of these actors have specific capabilities that may be more or less relevant to the PSS offer. As such, the framework is relevant to Small and Medium sized-Enterprises (SMEs), typically specialized in given domains and where the enterprise may be represented by a single decision centre. We consider the case of a PSS where the value network is configured around a focal company which puts the PSS offer on the market and supervises the creation of the full value network. As a hypothesis, the approach considers that each SME case study is contextualized and, thus, that no fully generic DSS, adaptable to any PSS case study, would be pertinent. In this perspective, the aim of the framework is to take into account these SME special features and facilitate and foster the specification, development and implementation of contextualized DSS by managing a generic decision-aid platform together with a contextualization process and mechanism.

The framework is based on a generic platform consisting of a set of diagnosis tools and most importantly the modelling and simulation facilities (Fig. 1). Such a platform is supported by a methodological procedure which rigorously structures the way to analyze and apprehend any case-study, then contextualize a decision-support system and, finally provide recommendations on the PSS value network configuration for the SME case study considered. Contextualization refers to (i) the application of the diagnosis tools to a given case study, and (ii) the tailoring process of the simulation model in this case study. Generalization represents the possible requirements that may be extracted from the case study regarding the generic applicability of the diagnosis

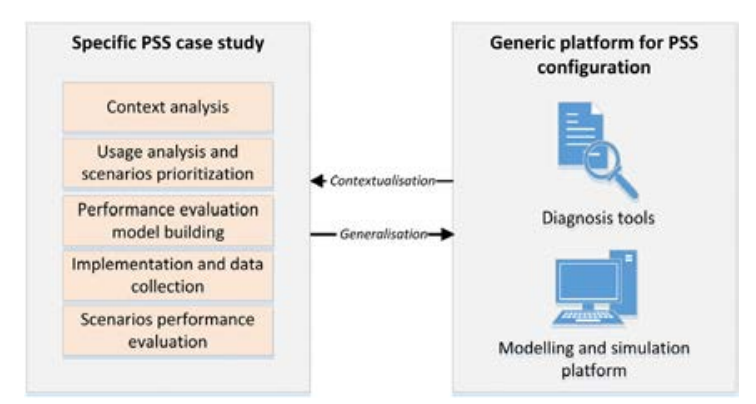

Fig. 1. Methodological framework for the development of PSS-oriented DecisionSupport Systems. tools and simulation model. These requirements contribute to continuous improvement of the generic platform.

The following steps are the backbone of the methodological guidance: context analysis, usage analysis and scenario prioritization, performance evaluation model building and scenario performance evaluation [14].

Context analysis combines the firm's mission, objectives and functional areas relating to these objectives. It consists in understanding the company's industrial context and competition factors. This relies on semi-structured interviews with the key PSS actors. The interviews are structured in a way that allows for the SWOT matrix and PESTEL diagram to be filled in for the focal company. ${ }^{1}$ In other words, the interviews address the following issues: company strengths, weaknesses, opportunities and threats and macro-environment characteristics, relating to PSS. However the scope of the context analysis can be broadened further according to the complexity of the product or manufacturing system. For instance, interviews may be followed up with identification and representation of key business processes, if needed. As such, this step provides insights into the PSS development opportunities and the main strategic capabilities of the actors involved with regard to the PSS.

Usage analysis and scenario prioritization aims at defining different PSS variants based on the possible distinct uses of the PSS and identifying the value-creation potential for the actors involved (provider, customer and other stakeholders). This step relies primarily on semi-structured interviews, brainstorming, and questionnaires to capture the expectations of both the customer and the actors involved in the PSS delivery. As regards the customer, the aim is to identify required and aspired-to functionalities throughout the product life cycle. The functionalities can be broken down into primary and secondary functions so as to facilitate the identification of services. As well as providing an analysis of value-creation factors for the various potential actors of the PSS value network, the aim is to identify opportunities for including more services within the offer whilst revealing any technical constraints the PSS implementation could face. During brainstorming interviews all the actors (i.e. value network, customer) are brought together in order to evaluate PSS-offer opportunities against customer requirements and find trade-offs if needed. Afterwards, several scenarios are defined in keeping with the expected uses of the PSS. Each scenario consists in a configuration of the PSS offer associated to a configuration of the PSS delivery network, specified by a combination of actors and roles within the network. Finally these scenarios are filtered in order to narrow the scope of the subsequent quantitative evaluation. The filtering criteria stem from the context analysis and stakeholder experience, and are defined during face-to-face meetings. Scenario prioritization consists in putting priorities on the key scenarios which will be submitted to further analysis. Prioritization is based on the experience of the PSS actors and the consideration of external factors such as environmental regulations and customer culture.

Performance evaluation model building (i.e. Quantitative modelling) aims at building performance evaluation models in keeping with the firm's objectives behind the PSS implementation. More specifically, this step is aimed at defining the performance indicators for each actor involved and identifying physical and financial flows that need to be modelled in order to enable indicator calculation by the use of simulation. Then, questionnaires are built upon these models and used for data collection. The subsequent performance indicators should comply with the

\footnotetext{
${ }^{1}$ SWOT (Strengths, Weaknesses Opportunities, Threats) and PESTEL (Politic, Economic, Social, Technological, Legal) are common strategic diagnosis tools oriented to both internal and external factors of a company.
} 
multi-actor perspective principle, meaning that the final set of performance measures should accommodate the points of view of all the actors of the PSS value network.

Implementation and data collection. Implementation refers to building the technical simulation environment. This task relies on well-established understanding of the case study context. Such good understanding ensures the consistency of the simulation model with the case study realm. Implementation is accompanied by data collection which is a challenging task because of the multiactor perspective adopted by the proposed approach and the heterogeneity of the required product and service-related data. The collection process involves different actors from the value network, depending on their roles and field of specialization. A systematic approach is adopted in order to mitigate the complexity of this step and consists in designing structured questionnaires specifying the required data and completing the missing data through interviews with the PSS actors.

Evaluate scenario performance is a critical step in supporting the decision-making process as it provides an evaluation of several alternative scenarios (consisting in a configuration of the offer and the associated network), thus helping to put the focus on the most interesting ones according to the performance measures. To this end, a three-stage process is deployed and consists in:

- Build an experimentation plan: this stage relates to the a priori identification of potential performance scenario drivers based on PSS actor experiences.

- Evaluating scenario performance: this stage uses simulation to compute the performance measures upon replicating the real operation of the value network actors.

- Identify performance drivers: this stage processes the output of the simulation (performance measures) to identify the most impacting drivers on the performance measures. The tools used at this stage are decision trees forming an efficient and comprehensive tool to identify the impact of different decision levels on the performance. Thresholds can be defined based on this analysis defining the circumstances under which the PSS implementation would be potentially successful.

This step provides insightful information on the viability of alternative scenarios, covering the points of view of various actors and drawing recommendations on which ones to choose: these conclusions remain the final responsibility of decision-makers.

\section{Simulation for PSS value-chain configuration}

As explained in section 1, the first objective of this methodological framework is rapid specification of contextualized Decision Support Systems for PSS configuration. These DSS are expected to represent the service- or industry-oriented processes at a sufficiently detailed level, so as to provide reliable reconstruction of the multiple performance factors, and then the indicators to be considered during the decision-making process. As mentioned above, the performance assessment proposed is based on a deterministic continuous simulation model [34]. The use of simulation entails 3 main steps:

- Simulator implementation. The simulator is built as an instantiation of the simulation model provided by the generic platform (Fig. 1). It enables simulation of the full range of scenarios selected for the case study: basically, it embeds (i) so-called 'fixed parameters' which instantiate characteristics of the PSS value network shared by all the scenarios, and (ii) 'configurable variables' used to differentiate the various scenarios.

- Configuration of scenarios. This step consists in selecting the right values of 'configurable variables' to represent a given scenario to be simulated. These configurable input parameters range from market data down to particular characteristics of value network activities.

- Generation and analysis of performance results. The results are structured in several graphs which can be adapted to the points of view of the actors of the case study. The results are generated over large periods of simulation which cover several years, depending on the requirements of the case study.

Implementation of the simulation model uses Visual Basic language. Interdependencies between the activities and flows characterizing the PSS value network processes are modelled using mathematical equations, cf. Eqs. (1)-(10), $\forall p \in\left\{1, \ldots, n_{p}\right\}$, such as $p$ a given simulation period, and $n_{p}$ the number of simulation periods. These represent the core of the simulation. The simulation algorithm is described below.

Calculate the number of required contracts (in months), according to the market volume during the period (Eq. (1)). Contracts can be defined as agreements the purpose of which is to mitigate risks by defining the obligations of the parties. Contracts contain defined service shares and times for each service [7]. In the current simulation algorithm, if the market volume exceeds the capacity made available through ongoing PSS contracts, then new contracts need to be launched.

$n_{\text {req }}^{p}= \begin{cases}\frac{M^{p}}{C_{p s s}}-n_{a v}^{p-1}, & \text { if }\left(\frac{M^{p}}{C_{p s s}}>n_{a v}^{p-1}\right) \\ 0, & \text { if }\left(\frac{M^{p}}{C_{p s s}} \leq n_{a v}^{p-1}\right)\end{cases}$

where $n_{r e q}^{p}$ refers to the number of required contracts during period $p, n_{a v}^{p-1}$ designates the number of available contracts at the end of period $p-1, M^{p}$ refers to market volume during period $p$, and $C_{p s s}$ is the capacity of the technical systems of the PSS.

If new contracts are needed, assign one or more contract types (characterized with a duration and service package) to the period (Eq. (2)). It is assumed that the share of each of the contracts in the portfolio is monitored by a rate defined by the PSS provider.

$n_{c}^{p}=n_{r e q}^{p} \times r_{c}$

where $n_{c}^{p}$ designates the number of contracts of type $c$ to be launched at the beginning of period $p, r_{c}$ refers to the rate of the contract of type $c$ in the contract portfolio.

Check the inventory of product items and returned products and update the in-progress production of required product items (Eq. (3)).The production is only run if the volume of returned product items plus its available inventory is insufficient to meet the required quantities over the next period.

$Q_{p r}^{i, p}= \begin{cases}Q_{r e q}^{i, p+1}-Q_{r e}^{i, p}-Q_{i n v}^{i, p}, & \text { if }\left(Q_{r e}^{i, p}+Q_{i n v}^{i, p}<Q_{r e q}^{i, p+1}\right) \\ 0, & \text { if }\left(Q_{r e}^{i, p}+Q_{i n v}^{i, p} \geq Q_{r e q}^{i, p+1}\right)\end{cases}$

where $Q_{p r}^{i, p}$ refers to the volume of production from item $i$ to be run during period $p, Q_{r e}^{i, p}$ designates the volume of returned product items $i$ expected at the beginning of period $p, Q_{i n v}^{i, p}$ refers to the inventory level of product item $i$ at the beginning of period $p$, and $Q_{r e q}^{i, p+1}$ is the volume of required product items $i$ during period $p+1$.

Update the list of ongoing contracts of the current period (Eq. (4)).

$n_{\text {ong }}^{p}=\sum_{c} \gamma_{c}^{p}, \gamma_{c}^{p}= \begin{cases}1, & \text { if } \operatorname{start}_{c}^{p} \leq p \leq e n d_{c}^{p} \\ 0, & \text { else }\end{cases}$

where $n_{\text {ong }}^{p}$ is the number of ongoing contracts, $\gamma_{c}^{p}$ is a Boolean which takes 1 if the contract is ongoing, 0 otherwise, $\operatorname{start}_{c}^{p}$ refers to starting period of contract $c$, and $e n d_{c}^{p}$ designates ending period of contract $c$. 
Update the list of available contracts at the end of the period (Eq. (5)).

$n_{a v}^{p}=\sum_{c} \mu_{c}^{p}, \quad \mu_{c}^{p}= \begin{cases}1, & \text { if } p \geq \text { end }_{c}^{p} \\ 0, & \text { else }\end{cases}$

where $n_{a v}^{p}$ is the number of available contracts at the end of period $p, \mu_{c}^{p}$ is a Boolean which takes 1 if contract $c$ ends during period $p$, 0 otherwise.

Update performance indicators (Eqs. (6)-(10)). The indicators are updated based on the output of the above computing steps. Eqs. (6) and (7) calculate the unit costs of given product item and service, respectively. These two results are used to calculate total costs incurred by a given actor in the value network, according to Eq. (8). The rent value per period is calculated according to Eq. (9), and the sales turnover of a given actor is deduced according to Eq. (10).

$C_{p d t}^{i}=\sum_{j} C_{a c t, j}^{i}$

where $C_{p d t}^{i}$ refers to unit cost of product item $i$, and $C_{a c t, j}^{i}$ designates the unit cost of activity $j$ involved in producing product item $i$.

$C_{\text {ser }}^{j}=\sum_{i} C_{p d t}^{i j}+\sum_{l} \alpha_{l}^{j} \cdot C_{p s l, l}^{j}$

where $C_{s e r}^{j}$ refers to unit cost of service $j, C_{p d t}^{i j}$ designates the unit cost of product item $i$ consumed by service $j, C_{p s l, l}^{j}$ refers to the unit cost of operators from category $l$ involved in service $j, \alpha_{l}^{j}$ is the average time spent by operators from category $l$ on service $j$.

$\operatorname{Cost}_{a}^{p}=\sum_{c} \sum_{j} C_{s e r, c}^{j} f_{j}^{p}+\sum_{i} C_{p d t, i}^{p}$

where $\operatorname{Cost}_{a}^{p}$ refers to total costs for actor $a$ during period $p, C_{\text {ser }, c}^{j}$ designates the unit cost of service $j$ included in contract $c, C_{p d t, i}^{p}$ refers to total cost of product item $i$ that is not included in service packages, during period $p$, and $f_{j}^{p}$ is the frequency of service $j$ during period $p$.

$r t_{c}^{p}=\sum_{j} C_{s e r, c}^{j} \times f_{j}^{p} \times m g_{s e r}+\sum_{i} C_{d e p, i}^{p} \times m g_{p d t}$

where $r t_{c, a}^{p}$ is the rent value of contract $c$ during period $p$ for actor $a$, $m g_{s e r}$ designates service margin rate, $C_{\text {dep }, i}^{p}$ refers to the depreciation cost of product item $i$ during period $p$, and $m g_{p d t}$ is the margin rate of product items.

$\operatorname{tr}_{a}^{p}=\sum_{c} r t_{c}^{p}$

where $\operatorname{tr}_{a}^{p}$ refers to the turnover of actor $a$ during period $p$.

These equations represent fundamental interrelationships shaping the simulation. It should be noted, however, that additional equations need to be developed if additional parameters are to be introduced into the model, notably to calculate additional performance indicators.

\section{Case study in the sludge treatment sector}

\section{Context analysis}

Usually, machining sludge generated by manufacturers is collected and treated by specialized companies. The idea suggested by a research and development institution involved in the current case study, calls for a fundamental shift away from getting rid of the sludge to making money out of it and saving natural resources. The traditional (a) and suggested (b) figures are represented in Fig. 2. It can be seen that beyond reusing the

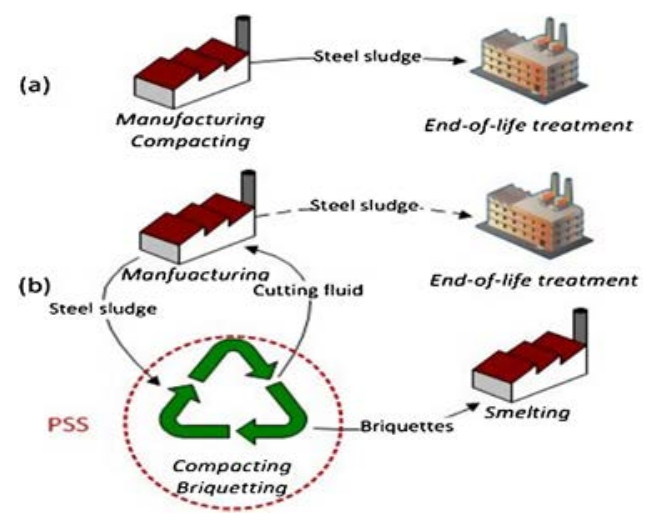

Fig. 2. Traditional (a) and innovative (b) configurations.

sludge, additional activities are needed, and thus new actors need to get involved. In the new figure (i.e. reusing the sludge) the main functionality of the PSS is to ensure compacting and briquetting of reusable sludge.

The actors involved in the value network are: (i) one manufacturer providing briquette-making equipment (i.e. equipment provider) ensuring the compacting and briquetting activities; thus briquette-making equipment is a part of the PSS solution, (ii) two manufacturers producing sludge and representing potential customers of the envisioned PSS solution, and (iii) two local smelters using electric arc furnaces to melt scrap steel and others metals: smelters are potential customers of the sludge sold as briquettes. For confidentiality reasons, specific information on the case companies and institutions will not be disclosed.

After identification of the above actors, a context analysis was carried out through collaboration between the authors of this paper and an SME working in design consultancy and oriented towards user analysis. At this level, the authors contributed to capturing potential customer requirements, before developing further analyses. Understanding of actor contexts relies on semistructured interviews with manufacturers who generate different types of sludge with equipment providers, manufacturers, and smelters.

\section{Usage analysis and scenario prioritization}

Collaborative work with the consultancy SME and the other PSS actors followed up by face-to-face meetings resulted in the identification of 18 alternative organizational scenarios for the value-creation chain. Each of these scenarios represents alternative answers to the following questions: (i) who should be the owner of the briquette-making equipment?, (ii) is it valuable to integrate an intermediate actor into the value network? and (iii) in which actor premises should the briquette-making equipment be placed, or should it be moving between actor premises? Afterwards, two meetings were held in order to filter scenarios according to (i) compliance to regulations, and (ii) added value for the other value network actors, including final customer. The subsequent organizational scenarios are the following:

- S1: the briquette-making equipment is sold to a manufacturer who takes care of the compacting, briquetting and maintenance operations, retrieves cutting fluids and sells briquettes to the smelter. This last role can be undertaken by an intermediate actor.

- S2: the briquette-making equipment is owned by its manufacturer and is located on the manufacturer's premises. The manufacturer uses it for the compacting and briquetting according to a rental contract. Maintenance can be included as a service in the contract and is performed by the briquette-making equipment 
owner; otherwise, it would be an internal activity of the manufacturer.

- S3: the briquette-making equipment is purchased by an intermediate actor who takes care of compacting, briquetting and maintenance operations and sells briquettes to the smelter.

- S4: the briquette-making equipment is owned by its manufacturer and moves periodically between different manufacturers.

\section{Performance evaluation model building}

Several indicators were established in order to evaluate the performance of the above scenarios. These indicators were selected to best fit the context of the case study and reflect the decisionmakers' concerns identified during the interviews. These concerns typically related to the need for an economic evaluation of the PSS and the multi-actor perspective required for this evaluation. Accordingly, for each of the actors involved, the following indicators were used: total costs, total benefits, profit and cash flow. Additional indicators were used to evaluate the performance at operational levels (e.g. remanufacturing). However, in coherence with the decision-aid required by the managers, in the following section the focus is put merely on economic evaluation.

\section{Implementation and data collection}

Equations 1 to 10 were implemented using visual basic, forming the backbone of the simulation tool. A Graphical User Interface (GUI) was designed to ease the configuration and simulation of the scenarios (i.e. inputs; activities, contracts, market, services, customer and roles data). Several graphics are generated out of the simulation and allow for tracking of the economic performances of the PSS actors (i.e. outputs). This results in a practical tool for configuring and evaluating the value network in the field of sludge treatment whose architecture is depicted in Fig. 3.

Data collection was structured as follows: first, a questionnaire was sent to three actors of the value network. The questionnaire was designed after clarifying the context and scenarios to be evaluated and after several face-to-face meetings with a equipment provider, two manufacturers and several smelters. The main data captured through the questionnaires can be summarized as follows: Variable costs of the activities including briquette-making and logistics (i.e. storage, transportation and installation) and data on taxes and margin rates; Annual cost of services and required product items; Contract type durations and Market demand and scrap price.

Activity costs are specified by the industrial partners in the responses to the questionnaires. The services for which data was

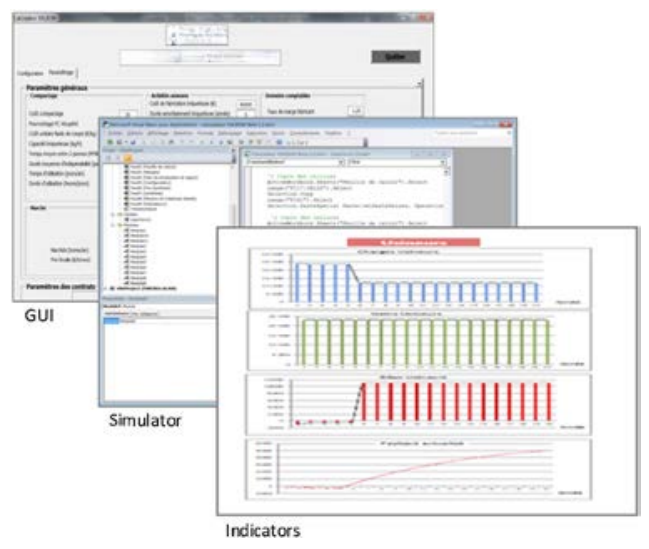

Fig. 3. PSS configuration tool architecture. gathered are: preventive maintenance, curative maintenance and exceptional waste treatment.

Preventive maintenance typically relates to the supply and change of spare parts of the compacting kit. The preventive maintenance cost is linked to the sludge type which requires more or less frequent intervention to change the compacting kit. A very hard sludge for example requires for the kit to be changed on a 6monthly basis, while a soft sludge requires one intervention every 18 months. Thus, three sludge types are considered and consist of very hard, standard, and soft sludge.

Curative maintenance consists of fixing the briquette-making equipment during unplanned down times. The annual curative maintenance cost is linked to the customer profile; the more autonomous the customers, the lower the costs incurred by the service provider. Three types of profiles are considered and consist of very autonomous, standard and slightly autonomous customers. Exceptional waste treatment ensures the processing of sludge during the down times of the briquette-making equipment.

Market demand refers to the yearly volume of sludge generated by the manufacturers and which needs to be processed by the briquette-making equipment. It is assumed that the market demand remains unaltered throughout the simulation periods (20 years). The values used for the simulation are shown in Table 1 . The lower market demand value is estimated collaboratively with the industrial partners, while other ones are generated by the authors to check the impact of the demand on the indicators.

After entering all the required data, the simulation is launched and follows the algorithm detailed in section 'Simulation for PSS value-chain configuration'. The period considered is one year and the simulation horizon is 20 years. The subsequent computation steps are as follows:

- Calculate the number of required contracts (in months), according to the market volume during current year

- If new contracts are needed, assign one or more contract types (characterized with a duration and service package) to current year

- Check the inventory of product items and returned products and update the in-progress production of required product items

- Update the list of ongoing contracts of the current year

- Update the list of available contracts at the end of the current year

- Update performance indicators

Although indicators should be taken with precaution because the simulation was partly based on quantitative hypotheses defined with the decision-makers (e.g. quantification of the relationship between user autonomy and curative maintenance cost), they still provide a good insight into the spins-offs of the newly-studied sector. Additionally, these hypotheses are consistent among the various scenarios analyzed, which made it pertinent to proceed to a comparative analysis of the scenarios.

\section{Evaluate scenario performance}

The interviews with the different actors involved helped to identify the potential economic drivers of the innovative sector for sludge treatment. The impacts of these drivers have to be analyzed through a simulation experimentation plan, detailed in Table 1 including the main candidate drivers and their different potential values. These values are chosen according to their relevance to the industrial context of the case study.

A simulation run represents a combination of the above drivers. The scenarios are simulated over a period of 20 years. Preliminary simulations showed that, in scenario 4 , the value network configuration starts to bear fruit only with high market volumes. 
Table 1

Simulation inputs.

\begin{tabular}{|c|c|c|c|c|c|c|c|c|}
\hline $\begin{array}{l}\text { Simulation } \\
\text { run }\end{array}$ & Scenario & $\begin{array}{l}\text { Market volume } \\
\text { (tonnes) }\end{array}$ & $\begin{array}{l}\text { Scrap } \\
\text { cost }(€)\end{array}$ & $\begin{array}{l}\text { Contract duration } \\
\text { (years) }\end{array}$ & $\begin{array}{l}\text { Sludge } \\
\text { type }\end{array}$ & $\begin{array}{l}\text { Customer } \\
\text { profile }\end{array}$ & $\begin{array}{l}\text { Waste } \\
\text { treatment } \\
\text { cost }(€)\end{array}$ & $\begin{array}{l}\text { Exceptional } \\
\text { waste treatment } \\
\text { cost }(€)\end{array}$ \\
\hline 1 & $\mathrm{~S} 1$ & 40 & 110 & NA & Standard & Standard & 200 & 350 \\
\hline 2 & $\mathrm{~S} 1$ & 200 & 110 & NA & Standard & Standard & 200 & 350 \\
\hline 3 & $\mathrm{~S} 1$ & 80 & 100 & NA & Standard & Standard & 200 & 350 \\
\hline 4 & $\mathrm{~S} 1$ & 80 & 120 & NA & Standard & Standard & 200 & 350 \\
\hline 5 & $\mathrm{~S} 1$ & 80 & 110 & NA & Very hard & Standard & 200 & 350 \\
\hline 6 & $\mathrm{~S} 1$ & 80 & 110 & NA & Slightly hard & Standard & 200 & 350 \\
\hline 7 & $\mathrm{~S} 1$ & 80 & 110 & NA & Standard & Low autonomy & 200 & 350 \\
\hline 8 & $\mathrm{~S} 1$ & 80 & 110 & NA & Standard & Full autonomy & 200 & 350 \\
\hline 9 & $\mathrm{~S} 1$ & 80 & 110 & NA & Standard & Standard & 150 & 350 \\
\hline 10 & $\mathrm{~S} 1$ & 80 & 110 & NA & Standard & Standard & 250 & 350 \\
\hline 11 & $\mathrm{~S} 1$ & 80 & 110 & NA & Standard & Standard & 200 & 300 \\
\hline 12 & $\mathrm{~S} 1$ & 80 & 110 & NA & Standard & Standard & 200 & 400 \\
\hline 13 & $\mathrm{~S} 1$ & 80 & 110 & NA & Standard & Standard & 200 & 350 \\
\hline 14 & $\mathrm{~S} 2$ & 40 & 110 & 5 & Standard & Standard & 200 & 350 \\
\hline 15 & $\mathrm{~S} 2$ & 200 & 110 & 5 & Standard & Standard & 200 & 350 \\
\hline 16 & $\mathrm{~S} 2$ & 80 & 100 & 5 & Standard & Standard & 200 & 350 \\
\hline 17 & $\mathrm{~S} 2$ & 80 & 120 & 5 & Standard & Standard & 200 & 350 \\
\hline 18 & $\mathrm{~S} 2$ & 80 & 110 & 3 & Standard & Standard & 200 & 350 \\
\hline 19 & $\mathrm{~S} 2$ & 80 & 110 & 7 & Standard & Standard & 200 & 350 \\
\hline 20 & $\mathrm{~S} 2$ & 80 & 110 & 5 & Very hard & Standard & 200 & 350 \\
\hline 21 & $\mathrm{~S} 2$ & 80 & 110 & 5 & Slightly hard & Standard & 200 & 350 \\
\hline 22 & $\mathrm{~S} 2$ & 80 & 110 & 5 & Standard & Low autonomy & 200 & 350 \\
\hline 23 & $\mathrm{~S} 2$ & 80 & 110 & 5 & Standard & Full autonomy & 200 & 350 \\
\hline 24 & $\mathrm{~S} 2$ & 80 & 110 & 5 & Standard & Standard & 150 & 350 \\
\hline 25 & $\mathrm{~S} 2$ & 80 & 110 & 5 & Standard & Standard & 250 & 350 \\
\hline 26 & $\mathrm{~S} 2$ & 80 & 110 & 5 & Standard & Standard & 200 & 300 \\
\hline 27 & $\mathrm{~S} 2$ & 80 & 110 & 5 & Standard & Standard & 200 & 400 \\
\hline 28 & S3 & 40 & 110 & NA & Standard & Standard & 200 & 350 \\
\hline 29 & S3 & 200 & 110 & NA & Standard & Standard & 200 & 350 \\
\hline 30 & S3 & 80 & 100 & NA & Standard & Standard & 200 & 350 \\
\hline 31 & S3 & 80 & 120 & NA & Standard & Standard & 200 & 350 \\
\hline 32 & S3 & 80 & 110 & NA & Very hard & Standard & 200 & 350 \\
\hline 33 & S3 & 80 & 110 & NA & Slightly hard & Standard & 200 & 350 \\
\hline 34 & S3 & 80 & 110 & NA & Standard & Low autonomy & 200 & 350 \\
\hline 35 & S3 & 80 & 110 & NA & Standard & Full autonomy & 200 & 350 \\
\hline 36 & S3 & 80 & 110 & NA & Standard & Standard & 150 & 350 \\
\hline 37 & S3 & 80 & 110 & NA & Standard & Standard & 250 & 350 \\
\hline 38 & S3 & 80 & 110 & NA & Standard & Standard & 200 & 300 \\
\hline 39 & S3 & 80 & 110 & NA & Standard & Standard & 200 & 400 \\
\hline 40 & S4 & 200 & 110 & 5 & Standard & Standard & 200 & 350 \\
\hline 41 & S4 & 200 & 110 & 5 & Standard & Standard & 200 & 350 \\
\hline 42 & $\mathrm{~S} 4$ & 200 & 110 & 5 & Standard & Standard & 200 & 350 \\
\hline
\end{tabular}

Furthermore, and based also on preliminary simulations, incorporating an intermediary turned out not to be profitable for any of the actors. Therefore, it will only be analyzed in scenario 3 .

Figs. 4-7 represent the regression trees of the equipment provider, manufacturers, smelters and intermediate-actor profit indicators, respectively. Regression trees are self-explanatory classifiers expressed as a recursive partition of the instance space [35]. Regression trees are used to help elucidate the most relevant drivers of the performance for each actor. The nodes represent the performance drivers which are in order of relevance; the most relevant drivers are linked to the root of the tree while drivers with the lowest importance are at the bottom. The branches are labelled with the separating input variables (i.e. drivers). The regression uses the partial least squares method. The tool used to support this analysis is the Salford Predictive Modeller ${ }^{\mathbb{R}}$ software suite. ${ }^{2}$ The graphical output of the analysis was edited using VISIO software in order to improve the graphical quality of the trees. In the Figs. 4-7, each of the nodes depicts data on a given class of profit values (e.g. average (AVG), number of instances $(N)$ ).

It is obvious from the regression trees that scenarios are the most important drivers of performance: this underlines that the decision regarding the selection of a good organizational scenario for the value-creation chain has strong economic consequences for the actors involved. The organization of the value network which defines the roles assigned to each actor has a notable leverage effect.

As regards the briquette-maker, scenarios 1,2 and 3 are more interesting than scenario 4 , as they induce positive average values of the profit. One unexpected result is that profit increases tremendously in the case of very hard sludge (node at bottom right-hand side). This can be explained by the fact that very hard

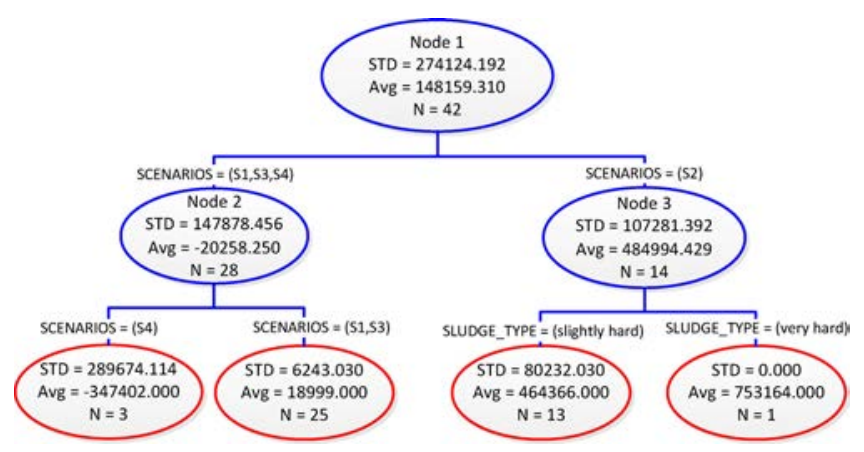

Fig. 4. Equipment provider profit regression tree. 


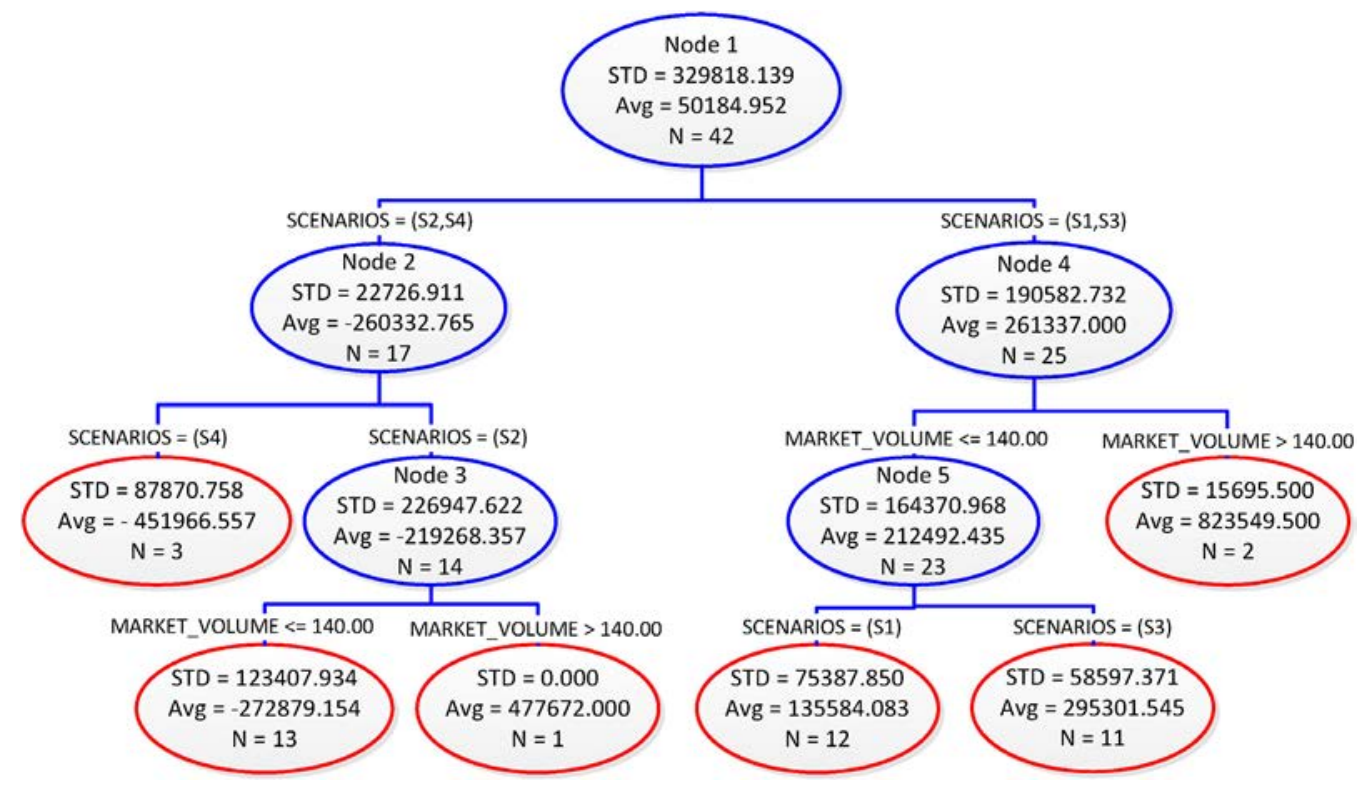

Fig. 5. Manufacturers' profit regression tree.

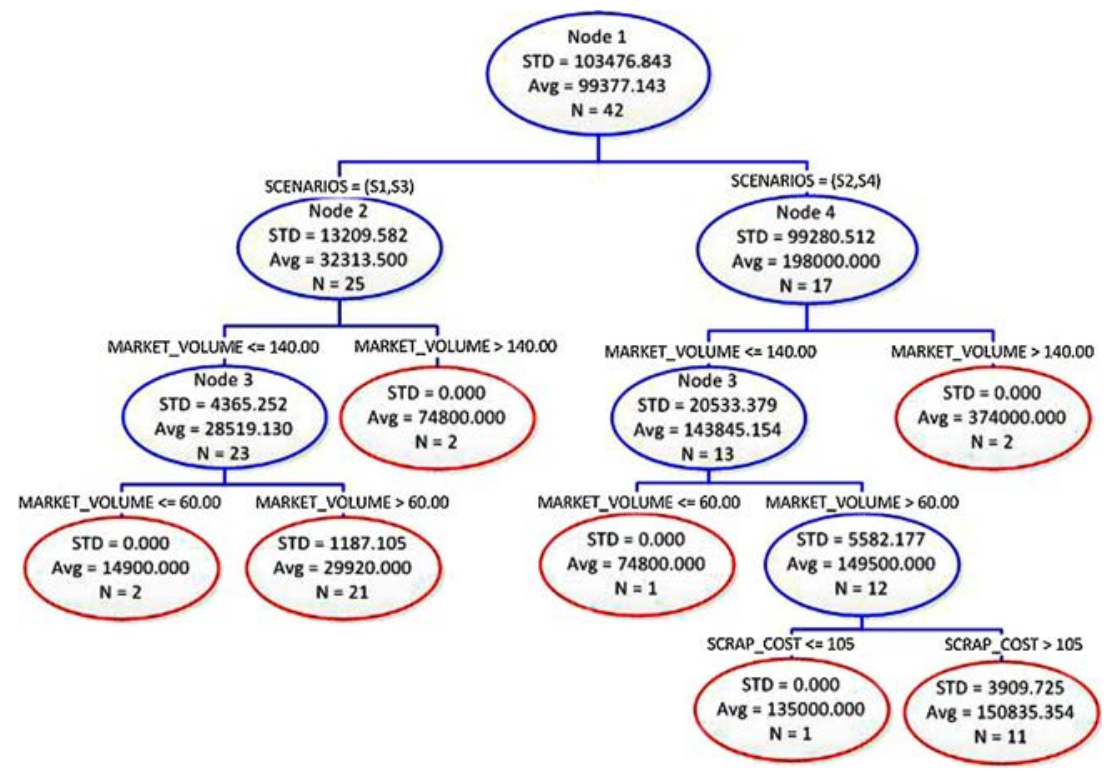

Fig. 6. Smelters' profit regression tree.

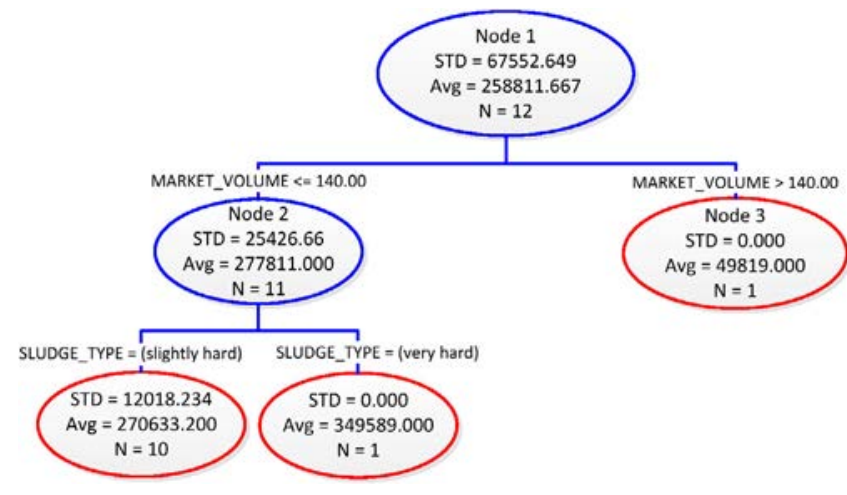

Fig. 7. Intermediary's profit regression tree. sludge requires more frequent equipment replacement (piston for pressing the sludge). As a consequence, revenues generated by equipment replacement will increase, hence leading to additional profit with the maintenance being offered as a service. Offering a maintenance service is thus profitable for the equipment provider. However, as shown in Fig. 4, scenario 2 is costly for the manufacturers who are supposed to pay for the compacting and briquetting service (monthly rental contract) and whose average profit has a negative value. This means that a trade-off should be made to cope with both equipment and service provider and manufacturer requirements. In fact, the first and third scenarios are the most interesting ones for manufacturers. Their differentiating variable is market volume which is proportional to the profit of the manufacturers. This is partly due to capacity utilization which increases with high volumes of sludge being treated. This figure is different in low-market volumes leading to underutilization of the briquette-making equipment. The smelters' 
regression tree, shown in Fig. 5, highlights that profit mainly depends on the scenario, market volume and scrap cost. In all scenarios, smelters are involved on a win-win basis. They can buy the briquettes generated by the compacting and briquetting activities while their purchasing costs do not exceed scrap costs. This is reflected by the reliance for their profit on market volumes and scrap costs. The most interesting scenarios for the smelters are the second and fourth ones which are actually not viable for the equipment provider. Finally, with regard to the intermediate actor's profit, the regression tree shows two important drivers: market volume and sludge type. These results are only valid in scenario 3 since the intermediary is not included in the other scenarios.

\section{Discussion}

The results of the case study uncovered several drivers of the profitability for the PSS stakeholders such as the market volume and most importantly the configuration of the value network (i.e. scenarios 1-4). It can already be noted that there is a willingness to go with the fourth scenario while extending the analysis to the regional scale. The willingness to go ahead with this scenario is motivated by the fact that:

The intermediate actor has no major added value and also limits the profit for smelters who are potential customers for the briquettes. Thus the sludge sector seems to be more viable with no intermediaries, handling only logistics activities. In other words, the complexity and cost of storage and transportation of the briquettes are not sufficient enough to warrant introducing an intermediary, or even outsourcing logistics activities.

In view of the simulation results, the profitability of the actors and particularly the equipment provider is leveraged by market volume. The latter culminates if we consider a regional scale since there are several small markets involved.

In order for the sludge sector to take root, a territorial perspective is needed. This ensures a more sustainable market relying on several manufacturers instead of a single one. However, dealing with a network of geographically-dispersed customers (i.e. manufacturers) creates new challenges. For instance, the transportation cost will increase tremendously with the increase in the routings among manufacturers. Distances to smelters will also impact transportation cost, depending on the distance between them and the manufacturers. This requires further analysis at more detailed levels which would consider the locations of manufacturers, equipment provider and smelters, as well as transportation means and costs.

These first conclusions on the case study highlight the relevance and peculiarities of simulation, in the field of PSS Design. Simulation enables the virtualization and anticipation of the service quality, which is challenging because of the intangible nature of services (they disappear at the moment they are produced). Due to the necessity to associate tangible and intangible components, PSS are complex systems to model dynamically: by the ability to decompose the dynamics of the overall system, into a set dynamic and more local subsystems interacting one with another, the simulation approach offers a good capacity to cope with this modelling-complexity. This is reinforced by the generalization/contextualisation framework proposed, which enables the re-use of generic PSS-oriented models, so as to easily derive contextualized decision support systems. This case study has demonstrated the added-value of simulation, to provide a rigorous and justified identification of the key influencing factors: by simulating the interactions amongst all performance drivers, the results of the analysis provide the decision-makers with a strong added-value on understanding how the system will operate and which key performance drivers should be managed as a priority. Additionally, simulation allows the evaluation of a wide range of alternative scenarios. However, clearly, simulation should not be considered as an optimization tool: the objective is not to recommend the 'best solution', but to provide the decision-makers with comparative assessments, which pointes out the key performance drivers that need to be focused on.

\section{Conclusions and research perspectives}

The proposed framework provides methodological guidance that meets complementary objectives: rapid specification, development then implementation of a simulation-based DSS adapted to a PSS context and operational evaluation and configuration of the PSS value network. It is supported by a generic modelling and simulation platform that is enriched with feedback from case studies. The core of the platform is a continuous deterministic simulation model that can also be tailored to take case study special features into account. The relevance of the simulation to the decision making process pertains to the need for an upfront assessment of the PSS profitability and the complexity of the PSS context.

The case study provides evidence of the relevance of the framework from the sludge sector. Beyond the added value of the method steps, the results help to shape the initial overview of an innovative sector for sludge treatment. The results of the case study indicate that there were several drivers of actor performance, such as market volumes, roles within the PSS value network and scrap costs. This provides a reasonable foundation for further investigation of the impact of some specific parameters. Depending on the benefits obtained by value-chain actors, an agreement should be made between them as to which scenario to explore.

While progress has been made to fill the gaps identified in the literature, the framework raises several important perspectives. For instance, the performance assessment of the PSS relies on traditional cost and revenue indicators; while it can be enriched further in keeping with the three PSS feasibility pillars: business viability, customer satisfaction and environmental soundness $[20,33]$. To this end, the framework can be extended to evaluate whether the PSS solution meets customer requirements. This avenue of improvement can benefit from existing research in this area [33,36-38]. Integrating business viability, customer satisfaction and environmental assessments is however challenged by the heterogeneity of the assessment criteria to be considered. Some attempts have already been made in this regard and provide starting points for such integration $[39,40]$. Subsequently, another area for improving the assessment involves the quantification of uncertainty. Basically, this would strengthen the decision aid provided to PSS actors.

Regarding the simulation model, several improvement areas can be identified. For instance, the current version of the model is more suited for the manufacturing sector and suggests that the demand can be easily estimated. While applying the framework to other domains such as the software industry would require fundamental changes of the simulation model. Further on, the model does not consider customer loyalty which may strongly impact contracts renewal and thus financial flows between the PSS stakeholders (e.g. renewal costs, refurbishment and reuse economies, etc.). Additionally, the scope of the simulation can be extended to the operational level involving production and delivery management. This is particularly relevant to the territorial perspective where the PSS provider should supply a network of geographically-dispersed customers. The need to consider the operational level is heightened further by the PSS offering variety. In fact, increasing offering variety induces internal complexity for the PSS provider in terms of resource allocation (e.g. personnel, products). The manufacturing process itself can be impacted if there are many alternative products included in the PSS offering. 
This implies that it might be interesting to check the feasibility of transferring concepts such as commonality and product modularity to the PSS context in order to leverage its potential for the PSS providers, the customer and the environment [41].

\section{Acknowledgment}

This research was developed with funding support from the French National Research Agency (ANR) through the National project, ServINNOV.

\section{References}

[1] Vandermerwe, S., Rada, J., 1988, Servitization of Business: Adding Value by Adding Services, European Management Journal, 64:314-324.

[2] Oliva, R., Kallenberg, R., 2003, Managing the Transition from Products to Services, International Journal of Service Industry Management, 14/2: 160-172.

[3] Johansson, P., Olhager, J., 2006, Linking Product-Process Matrices for Manufacturing and Industrial Service Operations, International Journal of Production Economics, 104/2: 615-624.

[4] Peillon, S., Pellegrin, C., Burlat, P., 2014, Exploring the Servitization Path: A Conceptual Framework and a Case Study from the Capital Goods Industry, Production Planning and Control, . http://dx.doi.org/10.1080/09537287.2015. 1033492. (in press).

[5] Baines, T.S., Lightfoot, H.W., Benedettini, O., Kay, J.M., 2009, The Servitization of Manufacturing: A Review of Literature and Reflection on Future Challenges, Journal of Manufacturing Technology Management, 20/5: 547-567.

[6] Cavalieri, S., Pezzotta, G., 2012, Product-Service Systems Engineering: State of the Art and Research Challenges, Computers in Industry, 63:278-288.

[7] Meier, H., Roy, R., Seliger, G., 2010, Industrial Product-Service Systems - IPS2, CIRP Annals - Manufacturing Technology, 59/2: 607-627.

[8] Boucher, X., 2012, Economic and Organizational Transition Towards ProductService Systems: The Case of French SMEs, Proc. of the 13th IFIP WG 5.5 Working Conference on Virtual Enterprises (PRO-VE 2012) (Bournemouth, United Kingdom), pp.26-34.

[9] Beuren, F.-H., Gomes-Ferreira, M.G., Cauchick-Miguel, P.-A., 2013, ProductService Systems: A Literature Review on Integrated Products and Services, Journal of Cleaner Production, 47:222-231.

[10] Marquès, G., Chalal, M., Boucher, X., 2012, PSS Production Systems: A Simulation Approach for Change Management, Proc. of IFIP International Conference on Advances in Production Management Systems (APMS 2012) (Rhodes, Greece),

[11] Tran, T.D., Ovtracht, N., Faivre d'Arcier, B., 2015, Modeling of Bike Sharing Demand, Proc. of the CIRP IPSS Conference (IPSS 2015) (Saint-Etienne, France),

[12] Lingegard, S., Lindahl, M., 2015, Life-Cycle Cost Strategies for Habors - The Case of Gothenburg Container Terminal, Proc. of the CIRP IPSS Conference (IPSS 2015) (Saint-Etienne, France),

[13] Aurich, J.C., Mannweiler, C., Schweitzer, E., 2010, How to Design and Offer Services Successfully, CIRP Journal of Manufacturing Science and Technology, 2/3: 136-143

[14] Medini, K., Moreau, V., Peillon, S., Boucher, X., 2014, Transition to Product Service Systems: Methodology Based on Scenarios Identification, Modelling and Evaluation, Proc. of 15th Working Conference on Virtual Enterprises (PROVE 2014) (Amsterdam, Netherlands),

[15] Alix, T., Zacharewicz, G., 2012, Product-Service Systems Scenarios Simulation Based on G-DEVS/HLA: Generalized Discrete Event Specification/High Level Architecture, Computers in Industry, 63/4: 370-378.

[16] Garetti, M., Rosa, P., Terzi, S., 2012, Life Cycle Simulation for the Design of Product-Service Systems, Computers in Industry, 63/4: 361-369.

[17] Alfian, G., Rhee, J., Yoon, B., 2014, A Simulation Tool for Prioritizing ProductService System (PSS) Models in a Carsharing Service, Computers \& Industrial Engineering, 70/4: 59-73.
[18] Chen, D., Chu, X., Yang, X., Sun, X., Li, Y., Su, Y., 2015, PSS Solution Evaluation Considering Sustainability Under Hybrid Uncertain Environments, Expert Systems with Applications, 42/14: 5822-5838.

[19] Taisch, M., Heydaria, M.R., Carosi, A., Zanetti, C., 2014, Service Performance Monitoring and Control Toolset, Procedia CIRP, 16:62-67.

[20] Mont, O.K., 2002, Clarifying the Concept of Product-Service System, Journal of Cleaner Production, 10/3: 237-245.

[21] Tukker, A., 2004, Eight Types of Product-Service System: Eight Ways to Sustainability? Experiences from Suspronet. Business Strategy and the Environment, 13/4: 246-260.

[22] Vargo, S., Lusch, R., 2004, Evolving to a New Dominant Logic for Marketing, Journal of Marketing, 68:1-17.

[23] Goedkoop, M.J., van Halen, C.J.G., Riele, H.R.M.te., Rommens, P.J.M., 1999, Product Service Systems, Ecological and Economic Basics, Dutch ministries of Environment (VROM) and Economic Affairs (EZ), The Hague, NL.

[24] Baines, T.S., Lightfoot, H.W., Evans, S., et al, 2007, State-of-the-Art in Product Service Systems, Proceedings of the Institution of Mechanical Engineers Part B: Journal of Engineering Manufacture, 221/10: 1543-1552.

[25] Marques, P., Cunha, P.F., Valente, F., Leitão, A., 2013, A Methodology for Product Service Systems Development, Procedia CIRP, 7:371-376.

[26] Morelli, N., 2006, Developing New Product Service Systems (PSS): Methodologies and Operational Tools, Journal of Cleaner Production, 14/17: 12951501.

[27] Kimita, K., Shimomura, Y., 2014, Development of the Design Guideline for Product-Service Systems, Procedia CIRP, 16:344-349.

[28] Kimita, K., Shimomura, Y., Arai, T., 2009, A Customer Value Model for Sustainable Service Design, CIRP Journal of Manufacturing Science and Technology, 1/ 4: 254-261.

[29] Lelah, A., Boucher, X., Moreau, V., Zwolinski, P., 2014, Scenarios as a Tool for Transition Towards Sustainable PSS, Procedia CIRP, 16:122-127.

[30] Lim, C.-H., Kim, K.-J., Hong, Y.-S., Park, K., 2012, PSS Board: A Structured Tool for Product-Service System Process Visualization, Journal of Cleaner Production, 37:42-53.

[31] Mannweiler, C., Siener, M., Aurich, J.C., 2010, Lifecycle Cost Oriented Evaluation and Selection of Product-Service System Variants, Proc. of the 2nd CIRP IPS2 Conference (Linkoping, Sweden), pp.21-28.

[32] Kimita, K., Tateyama, T., Shimomura, Y., 2012, Process Simulation Method for Product-Service Systems Design, Procedia CIRP, 3:489-494.

[33] Yoon, B., Kim, S., Rhee, J., 2012, An Evaluation Method for Designing a New Product-Service System, Expert Systems with Applications, 39/3: 31003108.

[34] Medini, K., Boucher, X., Peillon, S., Matos, C.D., 2015, Product Service Systems Value Chain Configuration - A Simulation Based Approach, Proc. of the CIRP IPSS Conference (IPSS 2015) (Saint-Etienne, France).

[35] Rokach, L., Maimon, O., 2005, Decision trees, in Maimon O, Rokach L, (Eds.) The Data Mining and Knowledge Discovery Handbook: A Complete Guide for Practitioners and Researchers. Springer, London.

[36] Geng, X., Chu, X., Xue, D., Zhang, Z., 2011, A Systematic Decision-Making Approach for the Optimal Product-Service System Planning, Expert Systems with Applications, 38/9: 11849-11858

[37] Mert, G., Waltemode, S., Aurich, J.C., 2014, Quality Assessment of Technical Product-Service Systems in the Machine Tool Industry, Procedia CIRP, $16: 253-258$

[38] Shimomura, Y., Nemoto, Y., Kimita, K., 2015, A Method for Analysing Conceptual Design Process of Product-Service Systems, CIRP Annals - Manufacturing Technology, . http://dx.doi.org/10.1016/j.cirp.2015.04.035. (in press).

[39] Xing, K., Wang, H.F., Qian, W., 2013, A Sustainability-Oriented Multi-dimensional Value Assessment Model for Product-Service Development, International Journal of Production Research, 51/19: 5908-5933.

[40] Chou, C.-J., Chen, C.-W., Conley, C., 2015, An Approach to Assessing Sustainable Product-Service Systems, Journal of Cleaner Production, 86/1: 277-284.

[41] Medini, K., Boucher, X., 2015, Decision Making Support to Steer Offering Variety During Production Planning, Proc. of the CIRP IPSS Conference (IPSS 2015) (Saint-Etienne, France),

[42] Mont, O., Lindhqvist, T., 2003, The role of public policy in advancement of product service systems. Special paper, Journal of Cleaner Production, 11/8: 905-914. 